\title{
Knowledge And Case Management Status On Acute Respiratory Infection Among Female Community Health Volunteers Of Kaski District-Nepal
}

\author{
Laxman Datt Bhatt $^{1 *}$, Lal Maya Gurung ${ }^{1}$ and Ramesh Shrestha ${ }^{2}$ \\ ${ }^{1}$ Pokhara University, School of Health and Allied Sciences, Kaski, Nepal \\ ${ }^{2}$ Possible Health, Nepal
}

Received: 22 February, 2018; Accepted: 05 May, 2018; Published: 17 May, 2018

*Corresponding author: Laxman Datt Bhatt, Pokhara University, School of Health and Allied Sciences, Kaski, Nepal, Tel: 9840066170;Email: laxmanbhattbph@gmail.com

\begin{abstract}
In Nepal, female community health volunteers are considered as front-line health service providers in a rejuvenated concept of primary health care by acting as a bridge between the health care delivery system and the community. A cross-sectional descriptive study was conducted in the Kaski District of Nepal with the objective to assess the knowledge and case management status of female community health volunteers on Respiratory Tract Infection. Two hundred FCHVs who completed CB-IMCI training were randomly selected.

Ninety-nine percent of FCHVs correctly defined ARI; 38.4\% of participants defined ARI's signs and symptoms correctly. Twentyseven percent of participants identified chest in-drawing as a danger sign of ARI. 96.5\% FCHVs knew about the organ affected by ARI and practice of ARI treatment. More than two-thirds of participants knew the respiratory rate cut off point and the Cotrimoxazole dosage for infants and children. Regarding ARI case management practice, $53.32 \%$ of FCHVs referred patients to a health facility, and $20.5 \%$ recommended home care and treatment. Neither the correct nor wrong responses about knowledge of ARI were significantly associated with education level or years of service.
\end{abstract}

It is concluded that the knowledge that FCHVs have about ARI in general is good, but some components of ARI knowledge are low. Supportive supervision, capacity building training, and commodities management are the factors that have the potential to improve health workers' motivation for better application of their knowledge and skills.

Keywords: Knowledge; FCHV; ARI; Nepal;

\section{Introduction}

Respiratory tract infection is defined as infective inflammatory changes in any part of the respiratory tract from the nasal mucosa to the alveoli with an alteration in the respiratory physiology [1]. Community health workers, an important component of the rejuvenated concept of Primary Health Care (PHC), act as a bridge between the health care delivery system and the community. Appropriate knowledge and communication skills in community level health workers are key to their confidence and essential for the success of the grass roots level health care system [2].
Female Community Health volunteers (FCHV's) are the frontline health care provider who serve in their respective residential area and commit themselves to work as pure volunteer. Nepal's FHCV Program represents a stable and effective approach towards improving key public health services. This includes imparting knowledge and skills for the empowerment of women, increasing awareness of health-related issues, Cotrimoxazole tablet distribution and Zinc tablet distribution and increasing the involvement of local institutions in promoting health care. Currently, there are around approximately 52,000 FCHVs in Nepal assisting with primary health care activities in rural and urban areas [3].

In addition to imparting Health Promotion and awareness to the community the major role of the FCHV is to promote the health and healthy behavior of mothers and community people for the promotion of safe motherhood, child health, family planning and other basic health services with the support of health personnel from the Sub Health Posts (SHPs), Health Posts (HPs) and Primary Health Care Centers (PHCCs) [4]. Female Health Volunteers are playing supportive role in the reduction of mortality rate of infant and child under five years of age. They specially focus on symptomatic treatment and refer the patient to grassroots level health care centre for further diagnosis. Nepal has made huge progress in the reduction of mortality rates of and infants and children under five years of age, but the reduction of neonatal mortality has been very sluggish. According to Nepal Demographic Health Survey (NDHS) 2011, approximately 86\% of mother sought services from FCHV during neonatal sepsis and treatment [5].

Approximately 156 million cases of childhood pneumonia occur each year, a majority of them in low- and middle-income countries. Nepal recorded high mortality of children under five years of age, averaging approximately 170 annual deaths per 1000 in the early 1980s, and it now reports 61 per 1000 and among all the respiratory tract infection cases 57.11 percent of cases were treated by Female Community Health Volunteer by symptomatic treatment $[6,7]$. 


\section{Materials and Method}

\section{Study Area}

The study was conducted in the Kaski District of Nepal. The Kaski District is a part of the Gandaki Zone and is one of the seventy-five districts of Nepal, a landlocked country in South Asia. It covers an area of $2,017 \mathrm{~km}^{2}$ and has a population of 492,098, according to the 2011 Census. This district lies at the centroid point of the country. The study was carried out from September 2016 to November 2016.

\section{Sample size Determination and Sampling Technique}

The sample size was determined by taking the $70 \%$ estimated case management status of female community health volunteers. Assuming a 5\% margin of error and a 95\% confidence level, the total sample size calculated was 200 FCHVs. For sampling, a simple random sampling method was used.

\section{Data Collection Technique}

Data were collected by using pre-tested, structured questionnaires and monthly progress reports from female community health volunteers. The questionnaire was based on variables included in the study.

\section{Data Analysis Method}

The data collected were checked for completeness and consistency, coded, entered and cleaned using EpiData version 3.1 and exported to SPSS version 20 statistical software. Based on the objective of the study, the data were analysed by using descriptive and inferential statistics.

\section{Data Quality Control}

The questionnaire was developed in the Nepali language and translated to English and back to Nepali. The questionnaire was pre-tested on $10 \%$ of the total sample in the Tanahun district, Gandaki Zone of Nepal before it was used for actual data collection.

\section{Ethical Considerations}

The study protocol was reviewed and approved by the Ethical Review Committee of Pokhara University Research Centre and a letter of permission was taken from the district Health office in Kaski, Nepal. All the study participants were fully informed about the purpose of the study, their right to refuse, the assurance of confidentiality and privacy during the interview. Oral informed verbal consent was obtained from every respondent. Strict confidentiality for the respondents was maintained through coding the questionnaires.

\section{Results}

\section{Sociodemographic Information}

A total of 200 mothers were interviewed. Table I shows some of the basic characteristics of the responding female community health volunteers.

\begin{tabular}{|c|c|c|}
\hline Characteristics & Frequency (n) & Percentage (\%) \\
\hline \multicolumn{3}{|l|}{ Age group } \\
\hline 30 and below & 3 & 1.5 \\
\hline $31-40$ & 51 & 25.5 \\
\hline $41-50$ & 86 & 43.0 \\
\hline $51-60$ & 48 & 24.0 \\
\hline 61 and older & 12 & 6.0 \\
\hline \multicolumn{3}{|l|}{ Ethnicity } \\
\hline Brahman|Chhetri & 122 & 61.0 \\
\hline Janjati & 58 & 29.0 \\
\hline Dalit & 12 & 6.0 \\
\hline Others & 8 & 4.0 \\
\hline \multicolumn{3}{|l|}{ Marital Status } \\
\hline Married & 180 & 90.0 \\
\hline Widow or single & 19 & 9.5 \\
\hline Divorced & 1 & 0.5 \\
\hline \multicolumn{3}{|l|}{ Education Level } \\
\hline Informal & 60 & 30.0 \\
\hline Primary Level & 39 & 19.5 \\
\hline Lower Secondary Level & 35 & 17.5 \\
\hline Secondary and Above & 66 & 33.0 \\
\hline
\end{tabular}

\section{Service related information}

More than one-third of participants' service length was between 21 to 25 years, followed by 11-15 years and 26-30 years and $2 \%$ of FCHVs had 31 or more years of service. The longest length of service was 35 years, and the shortest was 2 years of service. This study showed that more than half of the participants spent 8-10 hours per day in household chores (Table II).

\section{Knowledge about ARI definition}

Approximately 99\% of the respondents knew the correct definition of ARI. Only $1 \%$ of the respondents were found to lack knowledge about the proper definition of ARI. Regarding signs and symptoms of ARI, 38.4\% of the participants reported cough as a sign and symptom of Respiratory Tract Infection and $30.7 \%$ reported running nose as a sign and symptom of ARI (Table III).

\section{Knowledge of FCHVs about danger signs of ARI}

According to the CBIMCI guideline of the WHO, the danger signs in children are conditions such as chest in-drawing, unconscious, dehydration and unable to suck mother's milk. Chest in-drawing, unable to suck mother's milk, unconsciousness and dehydration are danger signs for children. Among all respondents, $27.0 \%$ of participants reported chest in-drawing as a danger sign; $26.7 \%$ of them responded unconscious. Unable to suck and dehydration was reported by equal numbers of participants i.e., $23.2 \%$ each (Table IV). 


\begin{tabular}{|c|c|c|}
\hline Characteristics & Frequency (n) & Percentage (\%) \\
\hline \multicolumn{3}{|l|}{ Years of service } \\
\hline 5 years and below & 13 & 6.5 \\
\hline $6-10$ & 29 & 14.5 \\
\hline $11-15$ & 33 & 16.5 \\
\hline $16-20$ & 20 & 10.0 \\
\hline $21-25$ & 68 & 34.0 \\
\hline $26-30$ & 33 & 16.5 \\
\hline 31 and above & 4 & 2.0 \\
\hline \multicolumn{3}{|c|}{ Time spend on household chores (hours) } \\
\hline $8-10$ & 114 & 57 \\
\hline 5-7 & 86 & 43 \\
\hline
\end{tabular}

\section{Knowledge of FCHVs about the place for ARI treatment}

Among the FCHVs, $51.2 \%$ responded health institution as the place for ARI treatment and about half of the respondents reported female community health volunteer is the place for ARI treatment (Table V).

\section{ARI case management practices by FCHVs}

More than half $(66.5 \%)$ of respondents reported that they refer ARI cases to nearby health institutions. 33.5\% of respondents reported that they prefer to treat ARI cases by using medicines themselves (Table VI).

\section{Association of different variables with ARI Knowledge}

The study reveals that there is no association between education level and knowledge of ARI and that the $p$ value of years of service was also more than 0.05 . Hence, there is no association between years of service and knowledge of ARI (Table VII].

Table III: Knowledge on definition of ARI $(n=200)$

\begin{tabular}{|l|c|c|}
\hline \multicolumn{1}{|c|}{ Characteristics } & Frequency (n) & Percentage (\%) \\
\hline Definition of ARI & & \\
\hline Disease of ENT and Lungs & 200 & 99.0 \\
\hline Disease of Digestive organ & 1 & 0.5 \\
\hline Disease of any part of body & 1 & 0.5 \\
\hline \multicolumn{1}{|c|}{ Total } & 202 & 100 \\
\hline *Multiple response & & \\
\hline
\end{tabular}

Table V: Knowledge on place of ARI treatment $(n=200)$

\begin{tabular}{|c|c|c|}
\hline Characteristics & Frequency (n) & Percentage (\%) \\
\hline \multicolumn{2}{|c|}{ Place of ARI treatment } & \\
\hline FCHV & 190 & 48.8 \\
\hline Health institution & 199 & 51.2 \\
\hline Total & 389 & 100 \\
\hline
\end{tabular}

Table IV: Knowledge on danger sign of ARI $(n=200)$

\begin{tabular}{|c|c|c|}
\hline \multicolumn{1}{|c|}{ Characteristics } & Frequency (n) & Percentage (\%) \\
\hline Danger sign & & \\
\hline Chest in drawing & 199 & 27.0 \\
\hline Unconscious & 197 & 26.7 \\
\hline Unable to suck mothers' milk & 171 & 23.2 \\
\hline Dehydration & 171 & 23.2 \\
\hline Total & 738 & 100 \\
\hline *Multiple response & & \\
\hline
\end{tabular}

\begin{tabular}{|c|c|c|}
\hline \multicolumn{3}{|c|}{ Table VI: ARI Case management practice by FCHV (n=200) } \\
\hline Characteristics & Frequency (n) & Percentage (\%) \\
\hline Case Management Practice & \\
\hline $\begin{array}{c}\text { Refer to health } \\
\text { institution }\end{array}$ & 133 & 66.5 \\
\hline $\begin{array}{c}\text { Treatment by } \\
\text { Medicine }\end{array}$ & 67 & 33.5 \\
\hline
\end{tabular}

Table VII: Association between different variables with knowledge of ARI

\begin{tabular}{|c|c|c|c|c|c|c|}
\hline Variables & Knowledge & & ${ }^{x 2}$ value & P-value & OR & $95 \% \mathrm{CI}$ \\
\hline Education Level & Below average & Average above & 0.070 & 0.886 & 0.927 & $0.529-1.624$ \\
\hline $\begin{array}{l}\text { Lower Secondary } \\
\text { and below }\end{array}$ & $56(56.6 \%)$ & $43(43.4 \%)$ & & & & \\
\hline Secondary and above & $59(58.4 \%)$ & $42(41.6 \%)$ & & & & \\
\hline \multicolumn{7}{|c|}{ Years of service } \\
\hline 21 year and below & $75(57.7 \%)$ & $55(42.3 \%)$ & & & & \\
\hline 22 year and above & $40(57.1 \%)$ & $30(42.9 \%)$ & 0.006 & 0.940 & 1.023 & $0.568-1.840$ \\
\hline
\end{tabular}




\section{Discussion}

Knowledge is both a determinant of practice and a reflection of what people practice. Given that ARI is one of the major diseases that cause child mortality, the knowledge of FCHVs about ARI plays crucial role in the prevention and management of the disease. This study revealed that ARI knowledge on FCHV was acceptable but filling the gaps in Case Management status. Additional in-depth training is needed to uplift their knowledge and skill. A similar study in the Anambra state of Nigeria and Uganda revealed that more than $80 \%$ of the participant's knowledge on Respiratory Tract Infection was acceptable [8, 9]. Similarly, a descriptive cross-sectional study conducted in Bhaktapur, Nepal, found that $83.9 \%$ of respondents had sound knowledge [10]. However, this is nearly double the rates seen in studies of eastern Nepal, where only $55.5 \%$ knew the definition of ARI and of Pakistan [11, 12].

The present study revealed that knowledge of signs and symptoms was better than was found by the study on community health workers in Nigeria and by mothers of eastern Nepal and was similar to the research conducted in Bangladesh and Uganda $[8,11,13$ \& 14]. The Department of Health Services annual report for $2015 / 16$ reveals that $57.11 \%$ of the total cases were treated at the FCHV level [15]. The present study revealed that $83.5 \%$ of participants classified children under five years of age into the correct age group, which is similar to the study from eastern Uganda [16]. In this study, most of the participants gave the correct answer regarding the respiratory rate cut-off point, which is almost similar to the study conducted on community health workers of western Uganda, where $79 \%$ of participants gave the correct classification of the respiratory rate cut-off point [17].

In this study, $80.5 \%$ of participants reported using the correct practice during the respiratory rate count of a restless child. Case management using community health workers (CHWs) has halved ARI mortality in children in Asia [18]. This might be due to a strong commitment of community health workers to strengthening the primary health care system. It is widely believed that education and years of service positively influence knowledge. The findings of the present study did not show this relationship. The association between educations, years of service and knowledge about ARI in the present study was inconsistent. However, another study conducted in Nepal and Uganda among FCHVs revealed that socio-demographic characteristics such as level of education, service years and workload affects the case management status of community health workers $[7,8]$. The results from this study showed that the interviewed FCHVs lacked knowledge about ARI. The areas of knowledge deficiency included age classification of the child, precautions during the respiratory rate count, dosage of Cotrimoxazole and precautions during stridor. It is important to reinforce education for the FCHVs, which possibly could result in better management of children with ARI.

\section{Conclusion}

Based on the findings of the study, it can be concluded that FCHVs' knowledge about ARI is good, but the case management status of ARI is inadequate. The government has given great responsibility to FCHVs but study reflects something is lacking about the work efficiency of FCHVs in the treatment and management of ARI cases. To increase the working efficiency of FCHVs, it is necessary to evaluate their knowledge level on a regular basis and practical skill related in-depth training and continuous skill enhancement programme should be to initiated to uplift the work efficiency of FCHVs.

\section{Acknowledgements}

The investigators would like to thank all the participants for their time and effort in responding to the questionnaires. I thankfully acknowledge the Supervisor and Faculty members of Pokhara University, Science and Technology.

\section{Availability of Data}

The data for this research is available, so we can contact you when you need our data for future processing.

\section{Conflict of Interest}

The author(s) declare that no competing interests exist.

\section{References}

1. Park JE. Preventive and Social Medicine. B is Dedic to Revere Mem my husband.

2. Haq Z and Hafeez A. Knowledge and communication needs assessment of community health workers in a developing country: a qualitative study. Hum Resour Health. 2009;7(1):59. Doi:10.1186/1478-4491-7-59

3. USAID. Nepal Family Health Program II: Local Health Governance Strengthening Program HFOMC. Technical Brief \# 28. 2003; www. nfhp.org.np.

4. Shrestha S. A conceptual model for empowerment of the female community health volunteers in Nepal. Educ Heal. 2003;16(3):318327. Doi:10.1080/1357628031000701607668

5. Department of Health Services. Annual Report. 2015;2071(72).

6. Pandit R\&. PD prasad Health hazards due to pesticide use and its protective/preventive practice among vegetable farmers in Bhaktapur district of Nepal. J Public Heal Assoc. 2013;5(1):13-18.

7. Services D of H. Annual Report. 2013;6(4).

8. Okankwo P, Osibogun A and Onwuasoigwe C. Knowledge and Practice of Different Cadres of Community Health Workers(CHWS) as Related to the Management of Acute Respiratory Infections(ARIS) in Anambra State,Nigeria. Niger J Clin Pract. 2002;5(1):37-40.

9. Wanduru P, Tetui M, Tuhebwe D, Okuga M, Nalwadda C and Ediau $M$ et al. The performance of community health workers in the management of multiple childhood infectious diseases in Lira, northern Uganda - A mixed methods cross-sectional study. Glob Health Action. 2016;9(1). Doi:10.3402/GHA.V9.33194

10. Gyawali M, Pahari R, Maharjan S and Khadka RR. Knowledge on acute respiratory infection among Mothers of under five year children of Bhaktapur. Int J Sci Res Publ. 2016;6(2):85-89.

11.Yengden B. What do mothers know about Acute Respiratory Infection : a case from eastern Nepal. 1999;(Vdc):1-8. 
12. Khan MH, Saba N, Anwar S, Baseer N, Syed S, Khan DI. ASSESSMENT OF KNOWLEDGE , ATTITUDE AND. 2006;4(2):57-60.

13. Rashid SF, Hadi A, Afsana K and Begum SA. Acute respiratory infections in rural Bangladesh: Cultural understandings, practices and the role of mothers and community health volunteers. Trop Med Int Heal. 2001;6(4):249-255. Doi:10.1046/j.13653156.2001.00702.x

14. Tuhebwe D, Tumushabe E, Leontsini E and Wanyenze RK. Pneumonia among children under five in Uganda: Symptom recognition and actions taken by caretakers. Afr Health Sci. 2014;14(4):993-1000. Doi:10.4314/ahs.v14i4.31

15. Department of Health Services Government of Nepal Ministry of Health and PopulationTeku, Kathmandu. Annual Health Report. Vol 71.; 2070.2014; www.dohs.gov.np.
16. Kalyango JN, Rutebemberwa E, Alfven T, Ssali S, Peterson S and Karamagi C. Performance of community health workers under integrated community case management of childhood illnesses in eastern Uganda. Malar J. 2012;11(1):282. Doi:10.1186/1475-2875$11-282$

17. Källander K, Tomson G, Nsabagasani X, Sabiiti JN, Pariyo G, Peterson S. Can community health workers and caretakers recognise pneumonia in children? Experiences from western Uganda. Trans R Soc Trop Med Hyg. 2006;100(10):956-963. Doi:10.1016/j. trstmh.2005.11.004

18. World Health Organization, Nepal Development Research Institute. Assessment of community based integrated management of neonatal and childhood illness program. 2017. 